\title{
Electronic discharge letters for deceased patients: clear communication with primary care
}

\author{
Authors: Katherine E Wensley, Nida Butt, Yanithra Perera and Apurba Chatterjee
}

\section{Aims}

To improve written communication between our hospital and primary care physicians, when informing them of patient deaths during hospital admission.

\section{Methods}

A survey was conducted with trainees to get their views regarding the concerns raised by general practitioners, and their suggestions for improvement.

A retrospective audit of hospital electronic discharge letters (EDLs) of deceased patients was performed between 31 January-28 February 2017 for 45 patients. Data were analysed and four further Plan, Do, Study, Act cycles were conducted. Subsequent cycles were conducted over 2-week periods, with 16 , 34,42 and 31 sets of notes audited, respectively.

Our interventions included a poster display in the bereavement office highlighting a standard new template which we generated, teaching at trust induction for trainees, a computer screensaver displayed December 2017-January 2018, and the attachment of the new template to every set of patient notes requiring a death certificate and EDL.

\section{Results}

Twenty-eight out of 31 (90.3\%) trainees responding to our survey suggested a change in the EDL for deceased patients. Table 1 illustrates the sequential and maintained improvement in EDLs completed fully in-line with our new template, and those with causes of death as diagnoses (a single domain of the template).

\section{Conclusion}

All of our above interventions resulted in improvements in correct completion rates of EDLs for deceased patients. From the success of this quality improvement project, our electronic patient records (EPR) team have approved a new template for deceased patients which will help to ameliorate any miscommunication with primary care. Our new EPR template will be operational from summer 2018.

Authors: Elderly Care, Royal Berkshire Hospital, Reading, UK

\begin{tabular}{|c|c|c|c|}
\hline $\begin{array}{l}\text { Audit } \\
\text { number }\end{array}$ & $\begin{array}{l}\text { Number } \\
\text { of EDLs } \\
\text { audited }\end{array}$ & $\begin{array}{l}\text { EDLs } \\
\text { completed } \\
\text { correctly (\%) }\end{array}$ & $\begin{array}{l}\text { EDLs with causes } \\
\text { of death as } \\
\text { diagnoses (\%) }\end{array}$ \\
\hline 1 & 16 & 12.5 & 50.0 \\
\hline 2 & 34 & 38.2 & 52.9 \\
\hline 3 & 42 & 76.2 & 95.2 \\
\hline 4 & 31 & 80.7 & 83.9 \\
\hline
\end{tabular}

\section{Conflict of interest statement}

The authors declare no conflicts of interests. 